\title{
Interleukin 8 released after acute myocardial infarction is mainly bound to erythrocytes
}

Robbert J de Winter, Annemieke Manten, Ype P de Jong, Rob Adams, Sander J H van Deventer, Kong I Lie

\begin{abstract}
Objective-To determine whether rapid clearance of interleukin 8 (IL-8) from plasma through binding to the erythrocyte chemokine receptor may be responsible for failure to detect IL-8 consistently after acute myocardial infarction.

Design-Plasma concentrations of IL-8 were measured at frequent intervals in 43 consecutive patients. In 21 of these, erythrocyte bound IL-8 concentrations were also measured. The influence of infarct size, type of treatment, and the presence of early successful reperfusion on IL-8 release was assessed.

Results-Peak IL-8 concentrations in plasma were raised in 31 of the 43 patients $(68 \%)$. Median plasma IL-8 concentrations were $16.0 \mathrm{pg} / \mathrm{ml}$ (range 2.4 to $225.0 \mathrm{pg} / \mathrm{ml}$ ) six hours after the onset of chest pain. Twelve hours after the onset of symptoms, plasma IL-8 concentrations had already returned to normal in 27 patients. In contrast, in 18 of 21 patients (86\%), erythrocyte bound IL-8 concentrations were raised at between 6 and 30 hours, with a median peak value of $59.8 \mathrm{pg} / \mathrm{ml}$ (range 19 to $148 \mathrm{pg} / \mathrm{ml}$ ). No correlation between peak creatine kinase MB and peak IL-8 (plasma or erythrocyte bound) was observed. There was a significant difference in peak plasma IL-8 concentrations between patients who underwent direct PTCA (19.4 pg/ml) and those who received conservative treatment $(9.9 \mathrm{pg} / \mathrm{ml} ; \mathrm{p}=0.0206)$, but no correlation with the presence of early successful reperfusion.

Conclusions-IL-8 is released in plasma after acute myocardial infarction and subsequently binds to red blood cells, resulting in only a transient rise of plasma IL-8 and a more prolonged increase of erythrocyte bound IL-8.

(Heart 1997;78:598-602)
\end{abstract}

Keywords: acute myocardial infarction; interleukin 8

Experimental models of acute ischaemic myocardial injury have indicated that with the onset of reperfusion an inflammatory response occurs, and this may contribute to tissue damage. ${ }^{12}$ Preventing the invasion of activated neutrophils in ischaemic-reperfused myocardium by blocking adhesion molecules on neutrophils or endothelium has been shown to limit infarct size in some, but not all, models of experimental myocardial infarction. ${ }^{3-5}$ Several cytokines, including tumour necrosis factor (TNF) and interleukin (IL) 6, play a role in activation of neutrophils, and circulating concentrations of these cytokines increase after acute myocardial infarction. ${ }^{6-9}$

IL-8 plays an important role in mediating neutrophil invasion in a variety of inflammatory processes. Cellular sources of IL-8 include mononuclear phagocytes, neutrophils, and a wide variety of other cell types, including endothelial cells. High tissue concentrations of IL-8 are thought to enhance neutrophil adherence and transmigration, whereas circulating IL-8 prevents neutrophil emigration. ${ }^{10-12} \mathrm{Be}-$ cause IL-8, when bound to erythrocytes, is incapable of stimulating neutrophils, ${ }^{13}$ the erythrocyte chemokine receptor seems to function as a scavenger receptor, limiting IL-8 bioactivity. ${ }^{14}$ IL-8 induces upregulation of the leucocyte adhesion molecule CD $11 \mathrm{~b} / \mathrm{CD} 18^{15}$ and therefore may play a key role in the pathogenesis of neutrophil induced reperfusion injury. In a canine model of myocardial ischaemia, reperfusion induced rapid and consistent induction of IL-8 mRNA expression. Antibodies directed against IL-8 blocked neutrophil mediated cytotoxicity for cardiac myocytes. ${ }^{16}$ In addition, it has been suggested that IL- 8 is a key participant in the cross talk between coagulation activation and cytokine cascades. ${ }^{17}$ Therefore IL-8 release may be a useful marker of coagulation and inflammatory activation in acute myocardial infarction. However, previous reports on circulating IL-8 following acute myocardial infarction in humans have been controversial. Some investigators have shown raised plasma concentrations of IL-8 after acute myocardial infarction, ${ }^{78}$ but others have been unable to confirm the finding. ${ }^{19}$ These contradictory results may, at least partly, be explained by rapid clearance of circulating IL- 8 from the plasma. One way by which IL- 8 is cleared from the plasma is by binding to a multispecific chemokine receptor on erythrocytes. ${ }^{13} 20$ The erythrocyte chemokine receptor has been shown to be identical to the Duffy blood group antigen and is capable of binding IL-8, GRO", and several other chemokines, including RANTES (Regulated on Activation of Normal $\mathrm{T}$ cell Expressed and Secreted chemokine) and MCP-1 (monocyte chemotactic protein 1$).^{21} 22$

We recently described a method for the detection of erythrocyte bound IL- $8 .^{23}$ In this study, we therefore investigated the time course and magnitude of both plasma and erythrocyte 
Table 1 Patient characteristics

\begin{tabular}{ll}
\hline & Number \\
\hline Men & $29(67 \%)$ \\
Women & $14(33 \%)$ \\
Age (mean (SD)) & $64(13)$ years \\
Anterior AMI & 15 \\
Inferior AMI & 23 \\
Non-Q wave AMI & 5 \\
PTCA & 14 \\
Thrombolysis & 17 \\
Conservative & 12 \\
Successful reperfusion & 26 \\
\hline
\end{tabular}

AMI, acute myocardial infarction; PTCA, percutaneous transluminal coronary angioplasty.

bound IL- 8 release in patients with acute myocardial infarction. We also assessed the influence of infarct size, method of treatment, and early successful reperfusion on IL-8 release.

\section{Methods}

PATIENTS

Patients were eligible for the study when presenting with chest pain of less than six hours' duration. Patients with infectious disease, fever on admission, or taking antiinflammatory drugs (with the exception of aspirin) were excluded. The protocol was approved by the medical ethics committee of our institution and all patients gave informed consent.

Patients with ST elevation of at least $2 \mathrm{~mm}$ in two contiguous precordial leads, $1 \mathrm{~mm} \mathrm{ST}$ elevation in two standard limb leads, or a previously unknown left bundle branch block were candidates for reperfusion treatment. All patients received aspirin $300 \mathrm{mg}$ on admission. If an interventional cardiologist and a catheterisation laboratory were available and the time course was such that the infarct related vessel could be opened within six hours of the onset of symptoms, primary percutaneous transluminal angioplasty (PTCA) was performed where there was electrocardiographic evidence of anterior acute myocardial infarction or inferior acute myocardial infarction with concomitant right ventricular infarction. Thrombolysis was started in all other patients eligible for reperfusion treatment. Patients received either accelerated rt-PA (alteplase) (Actilyse; Boehringer Ingelheim, Germany; dose according to GUSTO-I) or $1.5 \times 10^{6}$ units of streptokinase (Kabikinase; Kabi Pharmacia, Sweden). Thereafter, patients received unfractionated heparin intravenously with a target activated partial thromboplastin time of 60 to 90 seconds for 48 hours. Patients with ST depression or T wave abnormalities who were not candidates for

Table 2 Peak values of IL-8 in plasma and of erythrocyte bound IL-8

\begin{tabular}{lll}
\hline & Plasma $(n=43)$ & Erythrocyte bound $(n=21)$ \\
\hline PTCA & $19.4(5.8 \text { to } 165)^{\star}$ & $49.9(18.7$ to 120.1$)$ \\
Thrombolysis & $19.1(2.4$ to 224$)$ & $61.7(22.2$ to 148$)$ \\
Conservative & $9.9(4.3 \text { to } 30.6)^{\star}$ & $61.1(23$ to 142.4$)$ \\
Reperfusion & $16.6(2.4$ to 224$)$ & $58.5(18.7$ to 120$)$ \\
No reperfusion & $14.9(5.6$ to 62.1$)$ & $60.2(23$ to 148$)$ \\
\hline
\end{tabular}

Values are medians (range) in $\mathrm{pg} / \mathrm{ml}$. Differences between groups were tested with the Mann-Whitney U test for non-normally distributed data.

*Difference between plasma IL-8 in the PTCA group $v$ the conservative group, $\mathrm{p}=0.0206$. Other differences between groups were not significant. reperfusion treatment were given nitrates and unfractionated heparin intravenously with a target activated partial thromboplastin time of 60 to 90 seconds. $\beta$ Blockers, calcium entry blockers, or other drugs were prescribed at the discretion of the attending physician. The final diagnosis of acute myocardial infarction was based on a history of typical ischaemic chest pain, characteristic ECG changes, and a typical rise and fall of creatine kinase (CK-MB) activity, with a peak exceeding $8 \mathrm{U} / 1$.

BLOOD SAMPLING AND ASSAYS

Blood samples were collected from an antecubital vein on admission before any drugs were given, and at $4,6,8,12,16,20,24,30,36,42$, 48 hours after the onset of symptoms, in $4.5 \mathrm{ml}$ EDTA Vacutainers for IL- 8 and $4.5 \mathrm{ml}$ lithium-heparin Vacutainers for CK-MB assay. EDTA blood was immediately placed on ice $\left(4^{\circ} \mathrm{C}\right)$ and processed within 30 minutes. Blood samples were centrifuged for 20 minutes at $2000 \times g$ at $4^{\circ} \mathrm{C}$ and aliquots of plasma were stored at $-20^{\circ} \mathrm{C}$ for IL-8 measurement. For determination of erythrocyte bound IL-8, erythrocytes were isolated by centrifugation over Polymorphprep (Nycomed Pharma, Norway). Erythrocyte fractions were then washed four times with saline $(180 \times g, 10$ minutes) to remove residual platelets. The erythrocyte suspension was adjusted to the original packed cell volume, and the removal of leucocytes $(<200 /$ $\mathrm{ml})$ and platelets $(<700 / \mathrm{ml})$ was confirmed (Coulter counter STKR, Coulter, Hial-eah, Florida). The red blood cells were lysed by adding Triton X-100 at a final concentration of $0.1 \%$ and the lysates stored at $-20^{\circ} \mathrm{C}^{23}$

IL-8 concentrations in plasma and erythrocyte lysates were measured with a commercial enzyme linked immunosorbent assay kit (Central Laboratory of The Netherlands Red Cross Blood Transfusion Service, CLB, Amsterdam, The Netherlands), with a lower detection limit of $1.0 \mathrm{pg} / \mathrm{ml}$. Plasma concentrations of IL-8 in healthy individuals are below $10 \mathrm{pg} / \mathrm{ml}$ (manufacturer's product information). The presence of the Triton X-100 did not interfere with the detection of IL-8 in the assay. ${ }^{24}$ Since normal values for erythrocyte bound IL-8 were not available, concentrations of erythrocyte bound IL-8 were determined in 50 healthy volunteers.

\section{REPERFUSION}

Reperfusion status was assessed by angiography in patients who underwent primary PTCA. To assess successful reperfusion non-invasively in patients who received thrombolytic treatment, hourly changes on the ECG and clinical signs were monitored. Successful reperfusion was defined by the presence of the following conditions: (1) the symptoms of chest pain improved, whether or not this was preceded by an episode of reperfusion arrhythmia (accelerated idioventricular rhythm or sinus bradycardia); (2) there was a concomitant reduction in ST elevation of at least $50 \%$; (3) peak CK-MB occurred at or before 12 hours after the onset of symptoms. ${ }^{25}{ }^{26} \mathrm{In}$ all other cases attempted reperfusion was considered unsuccessful. 


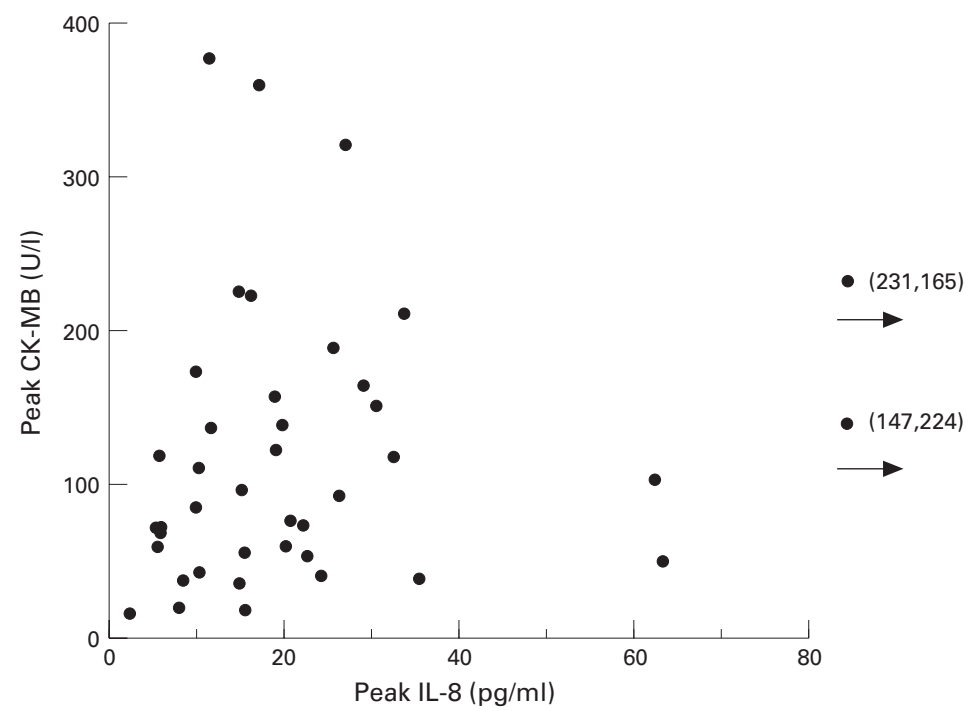

Figure 1 Scattergraph showing peak IL-8 concentrations in plasma on the $X$ axis and peak creatine kinase $M B$ isoenzyme (CK-MB) on the $Y$ axis, showing the lack of correlation. Each point on the graph represents the value in one patient. Two outliers are shown on the right side of the graph with their respective $C K-M B$ and IL-8 values. Neither erythrocyte bound $I L-8$ nor the sum of plasma and erythrocyte bound IL-8 was correlated with infarct size, as estimated from the peak $C K-M B$ value (data not shown).

\section{STATISTICAL ANALYSIS}

Median and ranges for peak values of plasma and erythrocyte bound IL-8 are reported. Differences between groups were tested by the Mann-Whitney $U$ test. Correlations between peak CK-MB and peak IL-8 were assessed with linear regression and Pearson's correlation. A p value of less than 0.05 was considered statistically significant. Values are given as mean (SD) or median (range).

\section{Results}

PATIENTS

Forty three consecutive patients were included in the study. Patient characteristics are summarised in table 1 , which shows a distribution of gender, age, and infarct location representative of patients with acute myocardial infarction. Fourteen patients underwent direct PTCA, 17 received thrombolytic treatment (alteplase,

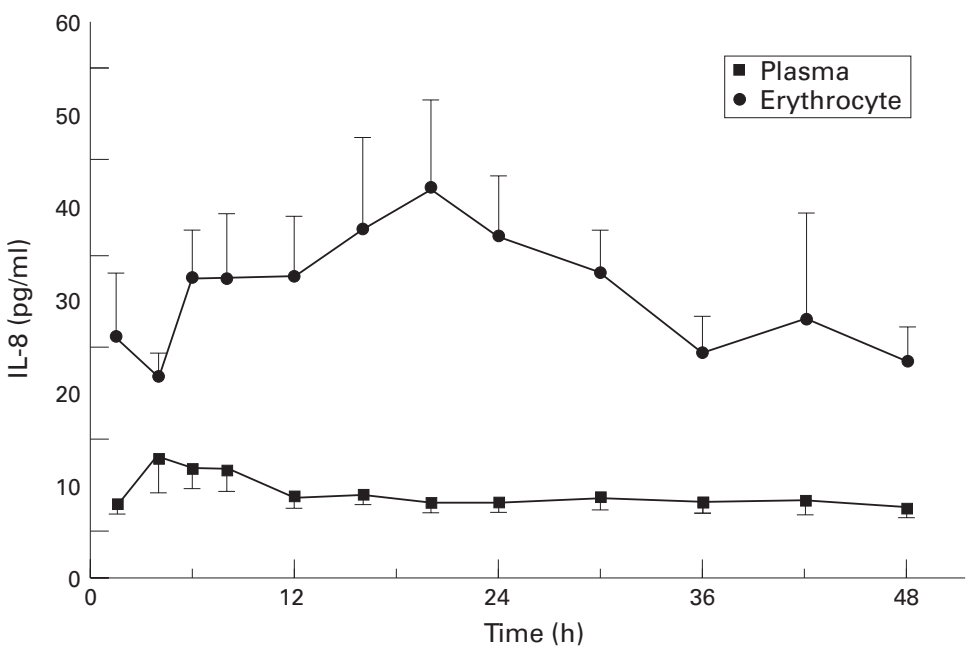

Figure 2 Mean plasma IL-8 and erythrocyte bound IL-8 from 21 patients with acute myocardial infarction. Error bars $=S E M$. Normal values were $10 \mathrm{pg} / \mathrm{ml}$ for plasma and $32 \mathrm{pg} / \mathrm{ml}$ for erythrocyte bound IL-8. Erythrocyte bound IL-8 concentrations peaked later than plasma concentrations, and were raised for longer. $\mathrm{n}=9 ;$ streptokinase, $\mathrm{n}=8$ ), and 12 were treated conservatively.

PLASMA IL-8

Plasma IL-8 concentrations were increased in 31 patients $(68 \%)$ and peaked early, usually at six hours after the onset of symptoms. In 27 patients (63\%), plasma IL-8 declined to normal values within 12 hours. Median peak IL-8 concentrations in plasma were 15.5 (40) $\mathrm{pg} / \mathrm{ml}$ (range 2.4 to 225 ). No correlation was apparent between peak plasma IL-8 and peak CK-MB, as shown in the scatterplot in fig $1\left(r^{2}=0.009 ; \mathrm{p}=0.54\right)$. There was no difference in peak plasma IL-8 concentrations between patients with and without early successful reperfusion (table $2^{2}$ ); however, there was a significant difference in peak plasma IL- 8 between the PTCA group and the conservative group $\left(\mathrm{p}=0.02\right.$, table $\left.2^{2}\right)$.

ERYTHROCYTE BOUND IL-8

In 50 healthy controls, mean erythrocyte bound IL-8 was 15.7 (8.2) pg/ml (upper limit of normal $=32 \mathrm{pg} / \mathrm{ml}$ ). Erythrocyte bound IL-8 concentrations were measured in 21 patients with acute myocardial infarction and was found to be 4.4 (1.3) times higher than simultaneous plasma IL-8 concentrations, as shown in fig 2 . In 18 of 21 patients ( $86 \%$ ), peak erythrocyte bound IL- 8 concentrations were above normal. Interestingly, in three of these patients plasma concentrations of IL- 8 were normal (<10 pg/ml). Median peak erythrocyte bound IL-8 was $59.8 \mathrm{pg} / \mathrm{ml}$ (range 19 to 148 ). Erythrocyte bound IL- 8 concentrations were raised from 6 to 30 hours, with peak values at 20 hours after the onset of symptoms. Erythrocyte bound IL-8 comprised $85(8) \%$ of total IL-8 per $\mathrm{ml}$ of whole blood. Peak erythrocyte bound IL-8 and peak CK-MB were not correlated $\left(r^{2}=0.001 ; p=0.889\right)$. Moreover, peak levels of erythrocyte bound IL-8 were not correlated with treatment or with early successful reperfusion.

\section{Discussion}

This study confirms that IL-8 is released following acute myocardial infarction. In our study, plasma concentrations of IL-8 were raised in $68 \%$ of patients with myocardial infarction. Moreover, we showed that approximately $85 \%$ of IL-8 in whole blood is bound by erythrocytes. Measurement of erythrocyte bound IL- 8 is time consuming, requires immediate processing of fresh blood samples, and depends on the interplay between dedicated nursing staff and laboratory facilities. We were therefore only able to measure erythrocyte bound IL- 8 concentrations in 21 of the 43 patients. Raised concentrations of erythrocyte bound IL- 8 were found in 18 of these 21 patients $(86 \%)$, three of whom had normal plasma IL-8 values.

Plasma IL-8 concentrations increased with an early peak at six hours after the onset of symptoms, and returned to normal values within 12 hours in the majority of patients. Abe et $a l^{18}$ also showed an early release of IL-8 in plasma after acute myocardial infarction in a 
small group of five patients. Similarly, Kanda et $a l^{27}$ found peak values at $4.4(1.2)$ hours after admission, which rapidly returned to normal in 24 patients. Moreover, these investigators found normal plasma concentrations of IL-8 in $33 \%$ of their patients, which is similar to the proportion of patients with normal IL-8 values in our study. In contrast, Siminiak et $a l^{19}$ failed to show IL-8 release after acute myocardial infarction.

Our data suggest that IL- 8 released after acute myocardial infarction is rapidly cleared from the plasma through binding to a chemokine scavenger receptor on erythrocytes. Indeed, binding of IL-8 to red blood cells has been shown previously. ${ }^{13} 23$ Hence failure to demonstrate IL-8 in plasma of patients following acute myocardial infarction may be due to this clearance mechanism.

When bound to erythrocytes, IL-8-and most probably other chemokines-is incapable of stimulating its normal target cells. ${ }^{13}{ }^{28}$ Since IL-8 may play an important role in transendothelial neutrophil migration induced by ischaemia/reperfusion, ${ }^{15}$ binding of IL- 8 by erythrocytes may thus prevent neutrophil activation at sites other than the site of injury. ${ }^{14}$

The importance of this pathway has been questioned, since a large population of healthy individuals do not express erythrocyte Duffy antigen.${ }^{29}$ Recently, however, it has been shown that postcapillary endothelial cells of these Duffy negative individuals do express Duffy antigen, but the functional importance of Duffy antigen expressed by endothelial cellsincluding a potential role as chemokine scavenger-remains to be determined..$^{30} 31$

In the present study, peak CK-MB values did not correlate with peak concentrations of plasma or erythrocyte bound IL-8. Although there was a significant difference in peak plasma IL-8 concentrations between patients who underwent direct PTCA and patients who were treated conservatively, no difference was found in peak erythrocyte bound IL- 8 values between these two groups.

Reperfusion status was assessed by angiography or non-invasively, as described previously. ${ }^{26}{ }^{32-34}$ Early successful reperfusion did not correlate with peak values of IL-8. This is somewhat surprising and in contrast to a report showing lower CRP and IL-6 values after successful reperfusion. ${ }^{35}$ However, minor differences or rapid changes in IL-8 released locally in the coronary vascular tree may be undetectable in the peripheral circulation.

We conclude that IL-8 is increased in plasma in about $70 \%$ of patients with acute myocardial infarction. Plasma IL-8 peaks early and returns to normal values in the majority of patients within 12 hours. In contrast, increased concentrations of erythrocyte bound IL- 8 are found in $86 \%$ of patients with acute myocardial infarction. Erythrocyte bound IL-8 values peak later and remain elevated for longer. Although there was a small difference in plasma IL-8 concentrations between patients treated with PTCA and patients treated conservatively, IL- 8 release after acute myocardial infarction appears not to be determined by infarct size, successful early reperfusion, or method of treatment.

We thank the medical and nursing staff of the coronary care unit of the Academic Medical Centre for their efforts and enthusiasm in performing this study, which was supported in part by a grant of the Dutch Heart Foundation (92-72)

1 Entman ML, Michael L, Rossen RD, Dreyer WJ, Anderson DC, Taylor DC, et al. Inflammation in the course of early myocardial ischemia. FASEB f 1994;5:2529-37.

2 Brady AJB, Williams FM, Williams TJ. Inflammatory injury in myocardial ischaemia. Clin Sci 1994;83:511-18.

3 Tanaka M, Brooks SE, Richard VJ, FitzHarris GP, Stoler $\mathrm{RC}$, Jennings RB, et al. Effect of anti-CD18 antibody on schemia and reperfusion in dogs. Circulation 1993;87:52635.

4 Simpson PJ, Todd RF, Fantone JC, Mickelson JK, Griffin D, Lucchesi BR. Reduction of experimental canine myocardial reperfusion injury by a monoclonal antibody (anti-Mo1, anti-CD11b) that inhibits leukocyte adhesion. $\mathcal{F}$ Clin Invest 1988;81:624-9.

5 Xin-Liang M, Lefer DJ, Lefer AM, Rothlein R. Coronary endothelial and cardiac protective effects of a monoclonal antibody to intercellular adhesion molecule-1 in myocar-

Maury CPJ, Teppo AM. Circulating tumor necrosis factoralpha (cachectin) in myocardial infarction. $\mathcal{f}$ Intern Med alpha (cachectin)

7 Latini R, Bianchi M, Correale E, Dinarello CA, Fantuzzi G, Fresco $\mathrm{C}$, et al. Cytokines in acute myocardial infarction: selective increase in circulating tumor necrosis factor, its soluble receptor, and interleukin-1 receptor antagonist. $\mathcal{F}$ Cardiovasc Pharmacol 1994;23:1-6.

8 Ikeda U, Ohkawa F, Seino Y, Yamamoto K, Hidaka Y, Kasahara $\mathrm{T}$, et al. Serum interleukin-6 levels become elevated in acute myocardial infarction. $7 \mathrm{Mol}$ Cell Cardiol 1992;24: $579-84$

9 Sturk A, Hack CE, Aarden LA, Brouwer M, Koster RW. Interleukin-6 release and the acute phase reaction in patients with acute myocardial infarction: a pilot study. 7 Lab Clin Med 1992;119:574-9.

10 Westlin WF, Gimbrone MA. Neutrophil-mediated damage of human vascular endothelium. Am f Pathol 1993;142: $117-28$.

11 Gimbrone MA, Obin MS, Brock AF, Luis EA, Hass PE, Hébert CA, et al. Endothelial interleukin-8: a novel inhibitor of leukocyte-endothelial interactions. Science 1989;246: 1601-3.

12 Rot A. Endothelial cell binding of NAP-1/IL-8: role in neutrophil emigration. Immunol Today 1992;13:291-4.

13 Darbonne WC, Rice GC, Mohler MA, Hébert CA, Valente AJ, Baker JB. Red blood cells are a sink for interleukin 8, a leukocyte chemotaxin. $\mathcal{F}$ Clin Invest 1991;88:1362-9.

14 Baggiolini M, Dewald B, Moser B. Interleukin-8 and related chemotactic cytokines-CXC and CC chemokines. Adv Immunol 1995;55:97-161.

15 Huber AR, Kunkel SL, Todd RF, Weiss SJ. Regulation of transendothelial neutrophil migration by endogenous interleukin-8. Science 1991;254:99-102.

16 Kukielka GL, Wayne Smith C, LaRosa GJ, Manning AM, Mendoza LH, Daly TJ, et al. Interleukin-8 gene induction in the myocardium after ischemia and reperfusion in vivo. $\mathcal{F}$ Clin Invest 1994;95:89-103.

17 Johnson K, Aarden LA, Choi Y, De Groot E, Creasey A. The proinflammatory cytokine response to coagulation and endotoxin in whole blood. Blood 1996;12:5051-60.

18 Abe Y, Kawakami M, Kuroki M, Yamamoto T, Fujii M, Kobayashi $\mathrm{H}$, et al. Transient rise in serum interleukin-8 concentration during acute myocardial infarction. Br Heart f 1993;70:132-4.

19 Siminiak T, Schroeder JM, Sticherling M, Wysocki H. Interleukin- 8 is not involved in the increased chemotactic activity of peripheral blood plasma during acute myocardial infarction. Basic Res Cardiol 1993;88:150-4.

20 Tilg H, Shapiro L, Atkins MB, Dinarello CA, Mier JW. Induction of circulating and erythrocyte-bound IL-8 by IL-2 immunotherapy and suppression of its in vitro production by IL-1 receptor antagonist and soluble tumor necrosis factor receptor (p75) chimera. F Immunol 1993; 151:3299-307.

21 Neote K, Mak JY, Kolakowski LF, Schall TJ. Functional and biochemical analysis of the cloned Duffy antigen: identity with the red blood cell chemokine receptor. Blood 1994;84: 44-52.

22 Horuk R. The interleukin-8-receptor family: from chemokines to malaria. Immunol Today 1994;15:169-74.

23 Manten A, Pajkrt D, De Winter RJ, De Jong YP, Jansen J, Ten Cate JW, et al. Erythrocyte-bound IL-8 and RANTES in human endotoxemia. I Endocrinol Res 1997;4:1-7.

24 Tilg H, Pape D, Trehu E, Shapiro L, Atkins MB, Dinarello interleukin-8 in humans during interleukin-1 therapy. $\mathcal{f}$ Immunol Methods 1993;163:253-8. 
25 Hohnloser SH, Zabel M, Kasper W, Meinertz T, Just H. Assessment of coronary artery patency after thrombolytic therapy: accurate prediction utilizing the combined analysis of three noninvasive markers. F Am Coll Cardiol 1991;18: $44-9$.

26 Zabel M, Hohnloser SH, Koster W, Prinz M, Kasper W, Just $\mathrm{H}$. Analysis of creatine kinase, CK-MB, myoglobin, and troponin $\mathrm{T}$ time-activity curves for early assessment of coronary artery reperfusion after intravenous thrombolysis. Circulation 1994;87:1542-50.

27 Kanda T, Hirao Y, Oshima S, Yuasa K, Taniguchi K, Nagai $\mathrm{R}$, et al. Interleukin-8 as a sensitive marker of unstable coronary artery disease. Am f Cardiol 1996;77:304-7.

28 Neote K, Darbonne WC, Ogez J, Horuk R, Schall TJ. Identification of a promiscuous inflammatory peptide receptor on the surface of red blood cells. F Biol Chem 1993;286: 12247-9.

29 Furie MB, Randolph GJ. Chemokines and tissue injury. $\mathrm{Am}$ f Pathol 1995;146:1287-301.

30 Hadley TJ, Lu Z, Wasniowska K, Martin AW, Peiper SC, Hesselgesser J, et al. Postcapillary venule endothelial cells in kidney express a multispecific chemokine receptor that is structurally and functionally identical to the erythroid isoform, which is the Duffy blood group antigen. $\mathcal{F}$ Clin Invest 1994;94:985-91.
31 Peiper SC, Wang Z, Neote K, Martin AW, Showel HJ, Conklyn MJ, et al. The Duffy antigen/receptor for chemokines is expressed in endothelial cells of Duffy negative individuals who lack the erythrocyte receptor. F Exp Med 1995;181: 1311-17.

32 Grande P, Granborg J, Clemmensen P, Sevilla DC, Wagner $\mathrm{NB}$, Wagner GS. Indices of reperfusion in patients with acute myocardial infarction using characteristics of the CK-MB time-activity curve. Am Heart f 1991;122:400-8.

33 Gorgels APM, Vos MA, Letsch IS, Verschuuren EA, Bar FW, Janssen $\mathrm{JH}$, et al. Usefulness of the accelerated idioventricular rhythm as a marker for myocardial necrosis and reperfusion during thrombolytic therapy in acute myoand reperfusion during thrombolytic therapy in

34 Clemmensen P, Ohman EM, Sevilla DC, Peck S, Wagner $\mathrm{NB}$, Quigley PS, et al. Changes in standard electrocardiographic ST-segment elevation predictive of successful reperfusion in acute myocardial infarction. Am $\mathcal{f}$ Cardiol 1990;66:1407-11.

35 Pietilä K, Harmoinen A, Hermens W, Simoons ML, Van der Werf $F$, Verstraete $M$. Serum C-reactive protein and infarct size in myocardial infarct patients with a closed versus an open infarct-related coronary artery after thrombolytic therapy. Eur Heart f 1993;14:915-19. 